\title{
The Role of English Proficiency in the Adaptation of Ukrainian Immigrant Children and Youth in Saskatchewan, Canada
}

\author{
Kateryna Bryzh \\ University of Saskatchewan \\ Veronika Makarova \\ University of Saskatchewan
}

\begin{abstract}
This article reports the results of a small-scale study examining the role of English language proficiency in the adaptation of Ukrainian immigrant children and youth to life in Saskatchewan, Canada. The main objective of the study was to describe issues related to English as a Second Language (ESL) proficiency as they are perceived by Ukrainian children and youth and by their parents. The second objective of the study was to explore the following factors in the adaptation process: age, gender, duration of stay in Canada, age upon arrival in Canada, ESL class attendance, school type (English as the language of instruction or bilingual), and level of English proficiency. A total of 60 participants (30 children/youth and 30 parents) took part in the study. The methodology (mixed quantitative/qualitative) involved semi-structured interviews with the children/youth participants, an evaluation of their ESL proficiency, and a questionnaire survey of parents' views on ESL-related adaptation difficulties experienced by children/youth. The results demonstrated that most Ukrainian immigrant children/youth reported that limited English proficiency was a major problem for them when they moved to Canada. The results of the study suggest that the difficulties experienced by a child who immigrates to Canada depend on the child's ESL speaking proficiency, general ESL proficiency, duration of stay in Canada, and age upon arrival in Canada.
\end{abstract}

Keywords: child and youth immigrants from Ukraine, Saskatchewan, English language proficiency, adaptation, English as a second language.

\section{INTRODUCTION}

Canada is well-known as a "multicultural nation" (Tavares 156) because it is composed of many diverse groups, including "immigrants and the descendants of immigrants" (Edmonston 78). In the census conducted in 2016, the proportion of immigrants in Canada was $21.9 \%$ of the country's population ("Canada's Population"). Upon settling in Canada, immigrants have to adjust to Canadian economic, social, and cultural norms, and the 
majority language(s) (Berry, "Conceptual Approaches"; Juang and Syed; Searle and Ward). This paper focuses on adaptation by one particular underrepresented immigrant sub-group-children and youth from Ukraine residing in Saskatchewan-to life in Canada. We consider how these issues are perceived by the children and youth participants as well as by their parents. This choice of topic is explained by an important role of Ukrainian diaspora in all of the prairie provinces in Canada (see, e.g., "About Ukrainians: Ukrainians in Saskatchewan") and by importance of issues of linguistic and cultural adaptation of immigrants, particularly of the vulnerable group of children and young adults.

\section{LITERATURE REVIEW}

\section{Adaptation of Immigrants to the New Home Country}

The theoretical framework of this study is grounded in earlier works on immigrant adaptation. Adaptation of immigrants is often discussed within a framework of acculturation theory as one of its final stages. Acculturation refers to the psychological and social changes that individuals and groups undergo during a prolonged exposure to a different culture (Berry, "Acculturation: Living"; Ward and Geeraert). Immigrants can acculturate in bidimensional (home and target cultures) or multi-dimensional models (their home and more than one target culture), as shown, for example, in Ferguson and Bornstein's study. Although the terms "adaptation" and "acculturation" are both used to describe immigrant adaptation (FernandezKelly; Perreira et al.; Ward and Kennedy, "The Measurement"), we use the term "adaptation" to avoid being limited by any specific acculturation model framework and to exclude misinterpretations of the term "acculturation" in the colonial sense in which the white middle class culture is "the standard" immigrants are expected to adhere to (Yosso 76).

Adaptation involves psychological and sociocultural domains (Searle and Ward). Psychological aspects of adaptation refer to emotional states, an ability to cope with stress, feelings of well-being, and the degree of satisfaction with the new environment and one's progress in adapting to it (Ward). Psychological adaptation is influenced by the immigrant's personality, the amount of available social support, and the number of required changes in the daily routines of life (Ward and Kennedy "Acculturation"; Wilson et al.). Socio-cultural adaptation requires abilities to solve external problems in the new surroundings, to learn a new culture, to develop one's social skills (Searle and Ward). Socio-cultural adaptation is affected by variables such as the length of residence in the host country, a cultural knowledge of the host country, the amount of interaction the 
immigrant experiences with individuals from other groups, the proximity of the home country to the host country, and the language proficiency and acculturation strategies of the immigrant (Ward and Kennedy, "The Measurement").

\section{Factors in the Adaptation of Adult Immigrants to the New Home Country}

Factors that can affect immigrant adaptation to a new home country include the immigrant's country of origin, the linguistic proficiency of the immigrant in the majority language of the host country; the immigrant's gender, age, age upon immigration, and the time elapsed since immigration. Since adaptation depends on the proximity of host and home cultures, the adaptation process can involve more hardship (ethnic, religious, social, educational stress) when the country of origin is significantly divergent, culturally, from the host country (Berry, "Conceptual Approaches"). Our study focuses on the linguistic aspects of adaptation of a particular age group of Ukrainian immigrants to life in Saskatchewan and contributes to building a more comprehensive picture of adaptation paths of immigrants.

The first essential factor in successful psychological and socio-cultural adaptation is immigrant proficiency in the majority language(s) of the host country (Andrade; Gonzales; McKay-Semmler and Kim; Ward and Kennedy, "The Measurement"). Well-developed language skills allow more successful communication and increase the amount of interaction between the immigrant and the new environment, enhancing an individual's adaptation (Lam; Ward and Kennedy, "The Measurement"). Insufficient language skills impede socialization, communication, and engagement with a new culture, negatively affecting adaptation (Gonzales). Immigrants in Canada with poor English or French proficiency experience high degrees of psychological stress, even after having lived in the country for a few years (Culhane; Xue).

Gender is another factor that has been shown to affect immigrant adaptation to a new country (Berry et al.; Carballo). Carballo found that females experience more adjustment problems than males. Young immigrant men have been shown to psychologically adapt to a new country better than young immigrant women, whereas young immigrant women are more successful than young immigrant men at socio-cultural adaptation (Berry et al. 319).

Age is a third major factor in immigrant adaptation to a new country (Berry et al.; Stiefel et al.). In an adult population, younger individuals tend to adapt to a new environment more quickly and with fewer problems than older individuals (Cheung et al.). In adolescent immigrants, an older age is associated with a higher stress level and poor mental health (Yeh et al.). However, with relatively few exceptions (such as Cheung et al.; Glozman and 
Chuang; Jia et al., "English Proficiency"; Lee and Chen), most studies of immigrants' adaptation in Canada have focused on adults.

Finally, the duration of the immigrant stay in Canada is another factor in adaptation considered in our study. Particularly among child immigrants, the length of time an immigrant has lived in Canada is correlated to the psychological distress of that immigrant (Yang).

Challenges Faced by Immigrant Children and Youth in Adaptation to a New Home Country

Immigrant children and youth (hereafter defined as "youth") are more vulnerable than immigrant adults, as immigrant youth face a number of extra challenges in their successful integration into a new society (Stodolska; Yeh et al.; Yang). Immigrant youth suffer from peer pressure at school, from difficulties in connecting to new educational systems and requirements, from racism and prejudice, from conflicting values of home and host cultures and resulting identity crisis, and from multiple cultural challenges (Berry et al.; Jia et al., "English Proficiency"; Mendes). Immigrant youth have to reestablish relationships with family members and friends after relocation to a new country (Stodolska). These issues can lead to fear, anxiety, aggression, learning difficulties, and low self-esteem. Immigrant youth are more susceptible than adult immigrants to identity problems and to worsening physical and mental health, and have higher probabilities of drug use (Ashworth; Yang).

Reaching a high level of proficiency in the majority language is a primary concern for immigrant youth (Lee and Chen). As language proficiency influences the academic success of immigrant youth (Portes), an inability to understand subject matter or teachers' explanations often leads to poor academic performance (Collier). Immigrant youth have to learn the target language of their host country and grasp new subject matter in their courses. As they are measured by the same standards as students born in the hostcountry (Short and Fitzsimmons), immigrant youth tend to have lower grades in school than youth born in the host country (Thompson et al.).

Social aspects of youthful immigrants' lives-such as interpersonal communication, making new friends, and fitting into social networksstrongly depend on their language proficiency (Lee and Chen; Schleifer and Ngo; Stodolska). Youth with higher levels of English proficiency have better psychological health, higher self-esteem, and better functional fitness in the new society (McKay-Semmler and Kim; Roberts and Chen). A delay in acquiring the majority language(s) of the host country by immigrant youth can result in language barriers, low self-confidence, higher risk of depression, and isolation from peers (Jia et al., "English Proficiency"; Perez; 
Portes and Zady; Roberts and Chen; Yen et al.; Yu et al.). Research has shown that second language acquisition among immigrant youth is affected by the age upon arrival, the length of stay in the host country, individual factors, the similarity of the first language (L1) to the second language (L2), the quantity and quality of L2 input, the type of school, the language used at home, and the density of the ethnic community (Hakuta et al.; Indefrey; Jia et al., "Longterm Language Attainment"; Moyer; Stevens; Yang).

Despite these challenges, child and adolescent immigrants form a valuable labour market source because they are more likely than their Canadian-born peers to complete post-secondary studies (Turcotte). Youthful immigrants also tend to develop bi/multicultural competencies in the local Canadian milieu as well as in the culture of their country of origin. In this way, immigrant youth contribute to social and cultural diversity in Canada (Turcotte). Therefore, the adaptation of immigrant children/youth to Canadian environment and a role of ESL skills in their adaptation process are highly pertinent topics with significant social outcomes.

The majority of immigrant studies conducted in Canada deal with populations in the major metropolises (Lam). Our study focuses on youth immigrants from Ukraine who were recently brought to Saskatchewan by their parents. Immigrants from Ukraine started settling in Canada in the 1890s (Kostyuk). In 2016, 3,365 Ukrainians relocated to Canada, bringing the number of immigrants from Ukraine residing in Canada to a total of 73,030 . Ukraine then placed fifteenth among countries originating Canadian immigrants. Most (90.6\%) of the new immigrants made homes in Ontario, British Columbia, Quebec, and Alberta ("Ukrainian Immigrants").

Ukrainian immigration to Canada increased, beginning in 1991 after the collapse of the Soviet Union. Recent Canadian immigrants from Ukraine belong to the fourth (ongoing) wave (Makarova and Hudyma). Characteristic features of the recent immigration to Canada from Ukraine are high levels of education and professional skills and a preference for settlement in urban rather than rural locations (Isajiw; Kostyuk). One of the factors attracting immigrants to Canada from Ukraine is the support of the well-established Ukrainian community, with its schools, cultural and educational institutions, and churches (Isajiw; Kostyuk). Yet, while adjusting to their lives in the new home country, these immigrants experience multiple difficulties including a feeling of isolation, discrimination at work, and issues with communication resulting from insufficient English language skills (Mouzitchka).

In Saskatchewan, the province where our study was conducted, the number of incoming immigrants from Ukraine increased steeply between 2006 and 2016 ("Focus on Geography"), reaching 14,821 per year from 2016-18; the inflow slightly declined (to 13,910 individuals) in 2019 (Duffin). In Saskatchewan, Ukrainian youth under fifteen years of age comprised $22.1 \%(10,615$ individuals) of recent immigrants, according to 
2016 Census data ("Focus on Geography"). Ukraine is the seventh highest country of origin of Saskatchewan immigrants (2.9\%, 3,280 individuals), and the sixth highest country of origin of immigrants $(2.8 \%, 1,320$ individuals $)$ ("Canada's Population"). Saskatoon has the highest number of immigrants $(45,160$ individuals or $15.6 \%)$ and recent immigrants $(18,585$ individuals or $6.4 \%$ ) in the province ("Focus on Geography"). Regina, the capital of Saskatchewan, has the highest proportion of immigrants per total population (36,910 individuals or $15.9 \%)$ and recent immigrants $(16,195$ or 7\%) ("Focus on Geography").

Most of the studies addressing Ukrainian Canadians in Saskatchewan cover Ukrainian ethnicity and diaspora, first language and culture maintenance, language attitudes and narratives (Denis; Halko-Addley and Khanenko-Friesen; Isajiw; Klymasz; Kordan; Makarova and Hudyma), and the experience of adult Ukrainian immigrants on the Canadian prairies (Lehr; Kostyuk).We did not find detailed studies of the connections between English language proficiency and problems with the adjustment of Ukrainian immigrant youth in the Canadian environment.

This study aims to: (1) describe adaptation difficulties faced by Ukrainian immigrant youth in Saskatchewan, with the focus on ESL proficiency-related difficulties as perceived by participants and their parents; (2) determine if and how ESL proficiency is related to the perceived adaptation of Ukrainian immigrant youth in Saskatchewan, and (3) establish whether other factors (age, gender, duration of stay in Canada, age upon arrival in Canada, ESL class attendance, language of instruction-English or bilingual) contribute to a successful adaptation of participants in Saskatchewan.

The research questions are:

- What challenges do Ukrainian youth in Saskatchewan name in their interviews as a part of their experience in the new country and which of these challenges are related to their level of English proficiency?

- Do the factors of age, gender, duration of stay in Canada, age upon arrival, school type, ESL proficiency, and ESL class attendance contribute to a successful adaptation of Ukrainian immigrant youth in Saskatchewan? 


\section{METHODOLOGY}

\subsection{DATA COLLECTION}

Data collection included interviews with Ukrainian youth. The subjects were asked about their adaptation difficulties. A questionnaire about adaptation difficulties encountered by immigrant youth was administered to the parents of the interviewees, and an English proficiency assessment was made of the Ukrainian immigrant youth.

\section{Interviews with Ukrainian Immigrant Youth}

Interviews are a method commonly employed to elicit research data directly from youthful informants (Stodolska; Yeh et al.). A face-to-face semistructured interview allowed us to clarify the participant's understanding of the interview questions and enabled us to ask additional questions to clarify significant details. The interviews were recorded with a Zoom H2n Handy Recorder in MP 3 format, and interview transcripts were manually produced by the first listed author and subjected to data analysis. The interview included three demographic questions and thirteen research questions covering the main challenges related to the ESL proficiency, the level of adaptation to the new country, and the current language use of the participant (see Appendix 3). We addressed four research questions that are directly related to adaptation difficulties frequently encountered by immigrants. The interview was conducted in the language (Ukrainian or English) chosen by the participant. The questions were printed on a lettersize page and read to the participant by the interviewer (the first listed author).

\section{Questionnaire Construction}

Questionnaires are frequently used to explore the level of immigrant adaptation to the host country (Feliciano; Jia et al., "English Proficiency"; Stodolska). Since questionnaires do not work well with young children, we designed a questionnaire in which parents could provide information about their children's and adolescents' English skills and their adaptation to Canada after immigration. The questionnaire (Appendix 4) contained thirtyseven questions. Of these, ten questions were related to the immigrant's demographics and background (section A). Research questions were introduced in section B (ten questions related to the immigrant's adaptation in the new country and his/her ESL proficiency), section C (five questions asked regarding the parent's estimate of the child's English proficiency), 
section D (seven questions asked about the child's adaptation and ESL proficiency), and section E (five open-ended opinion questions). Due to article length limitations, we report only parents' answers to the questions asked in section B (Appendix 4) because the parent responses in section B are the most crucial for understanding of the role of ESL proficiency in youth adaptation to Canada. The questionnaire was translated into Ukrainian, and the texts were verified by three individuals who are bilingual in Ukrainian and English. One parent of each participating youth was asked to fill out the questionnaire either in Ukrainian or in English.

\section{English Proficiency Assessment}

To determine whether language proficiency is involved in the reported issues with ESL, we conducted an English proficiency assessment of youth participants. The English proficiency of the participant was calculated by measuring vocabulary and reading skills and was evaluated with the help of the Nation 2001-Recognition test ("Levels Test (Recognition)"), which is available for free download and has a simple structure (see also Zahar et al.). As listening is an active interpretive process (Lynch and Mendelsohn), our study followed Communicative Language Teaching (CLT) comprehensionbased techniques. These techniques are grounded in skills "needed for constructing and communicating meaning" and are widely used to evaluate listening skills (Goh 188). We employed one of the common CLT listening response formats: multiple choice and True/False (Goh 189) following the pattern offered in an online listening quiz "Test Your Listening 2016." We used the audio of the second part of the "Test Your Listening" online quiz (a story about pets that would appeal to the youthful participants), but we expanded the scope of the questions (from a choice between two options to a choice among three options) and modified the questions to make them more appropriate for the age range of the participants. The test was piloted with two participants, who had no problems completing the task. Every youth participant was requested to listen to the audio excerpt and answer fourteen follow-up listening comprehension questions (printed on one page). The listening skills' score was extracted based on the number of correct answers to the questions.

To evaluate the speaking skills of youth participants, we employed a picture-description task frequently used in previous studies to elicit speech samples from children (Makarova et al.; Páez). Every speech sample was evaluated by an independent ESL expert (a certified TEFL instructor with over six years' ESL teaching experience) according to a five-point scale in which 5 was "excellent," 4 - "very good", 3 - "good", 2 - "satisfactory", 1 "minimal skills" (See Appendices 1-2 for details of skills assessment tasks). 
Finally, an overall language proficiency score was calculated for each participant as an average of their individual score for each given task (vocabulary/reading, speaking, and listening).

\section{Recruitment Strategies and Eligibility Requirements}

Participating immigrant youth and their parents were recruited via purposive sampling on a voluntary basis via posters and flyers placed in Ukrainian stores, the Ukrainian bilingual school, and Ukrainian churches in Saskatoon. The eligibility criteria for youth participants were set as follows:

- youth eight-fourteen years old, who were born in Ukraine, were permanent residents of Saskatchewan, and had lived in Saskatchewan for at least six months;

- youth who did not attend English courses in Ukraine apart from their regular school curricula.

\section{Participants}

Participants' families immigrated to Canada from Ukraine and resided in the province of Saskatchewan when the data were collected. Thirty Ukrainian immigrant youth were interviewed and completed the English proficiency tasks. Participants from Saskatoon (23), Yorkton (2), Lloydminster (4), and North Battleford (1) took part in the study (Table 1).

Table 1. Demographic information of youth participants.

\begin{tabular}{|l|l|l|l|l|l|l|l|l|l|}
\hline \multicolumn{2}{|l|}{ gender } & \multicolumn{2}{l|}{ age, yrs } & \multicolumn{2}{l|}{$\begin{array}{l}\text { age on arrival, } \\
\text { yrs }\end{array}$} & \multicolumn{2}{l|}{$\begin{array}{l}\text { time in Canada, } \\
\text { yrs }\end{array}$} & \multicolumn{2}{l|}{$\begin{array}{l}\text { school (by } \\
\text { lang.) }\end{array}$} \\
\hline M & F & 8 to 10 & 11 to 15 & 4 to 6 & 7 to 14 & up to 3 & over 3 & Engl & Ukr \\
\hline 17 & 13 & 15 & 15 & 15 & 15 & 15 & 15 & 20 & 10 \\
\hline
\end{tabular}

The questionnaire was filled out by thirty parents: twenty-seven (90\%) mothers and three $(10 \%)$ fathers between the ages of twenty-eight and forty years. All participants were informed about the goals of the study and their right to withdraw from the study. Every participating parent signed a consent form, and every youth participant signed an assent form. 


\subsection{DATA ANALYSIS}

Interviews with youth participants provided mostly qualitative data.

Qualitative Analysis of Youth Interview Transcripts and Quantitative Analysis of Parents' Questionnaire Entries

To identify the main areas of difficulty related to English proficiency and adaptation experiences that Ukrainian immigrant youth encountered after their relocation to Canada, content analysis with open coding (Erlingsson and Brysiewicz) was manually performed on the transcripts obtained from the thirty semi-structured interviews. The researchers compiled a list of themes and did their coding together so that agreement could be reached regarding which key-words and phrases were related to which theme.

\section{Quantitative Data Analysis}

Quantitative methods (Kruskall-Wallis H test) were also used to compare parents' responses to survey questions by their children's group (broken by gender, age, type of school, English proficiency). We employed a Pearson two-tail correlation analysis to analyze the youths' measured proficiency parameters vis-a-vis parents' estimates of their children's adaptation difficulties. The quantitative data from the parents' questionnaire and the participating youths' test scores were tabulated along with the social variables: age, gender, length of stay in Canada, choice of school, ESL class attendance. Statistical analyses (Kruskal-Wallis $\mathrm{H}$ tests and Pearson correlations) were performed in Microsoft Excel 2016.

\section{RESULTS}

\subsection{ISSUES IMPEDING ADAPTATION IDENTIFIED BY UKRAINIAN IMMIGRANT YOUTH IN} THEIR INTERVIEWS

The transcripts of the interviews with thirty immigrant youth were analyzed (open coding) to identify whether the participants reported any adaptation difficulties connected with their level of English proficiency. Participants identified a range of ESL related issues in the answers to interview questions "Could you please tell me about the main difficulties you have experienced after arriving to Canada?" and "Did you have any difficulties with English?" Their answers are summarized in Figure 1. As ESL issues were raised in 
answers to both questions, the answers to these two questions were analyzed together.

Figure 1. ESL-related problems identified in interviews with immigrant youth.

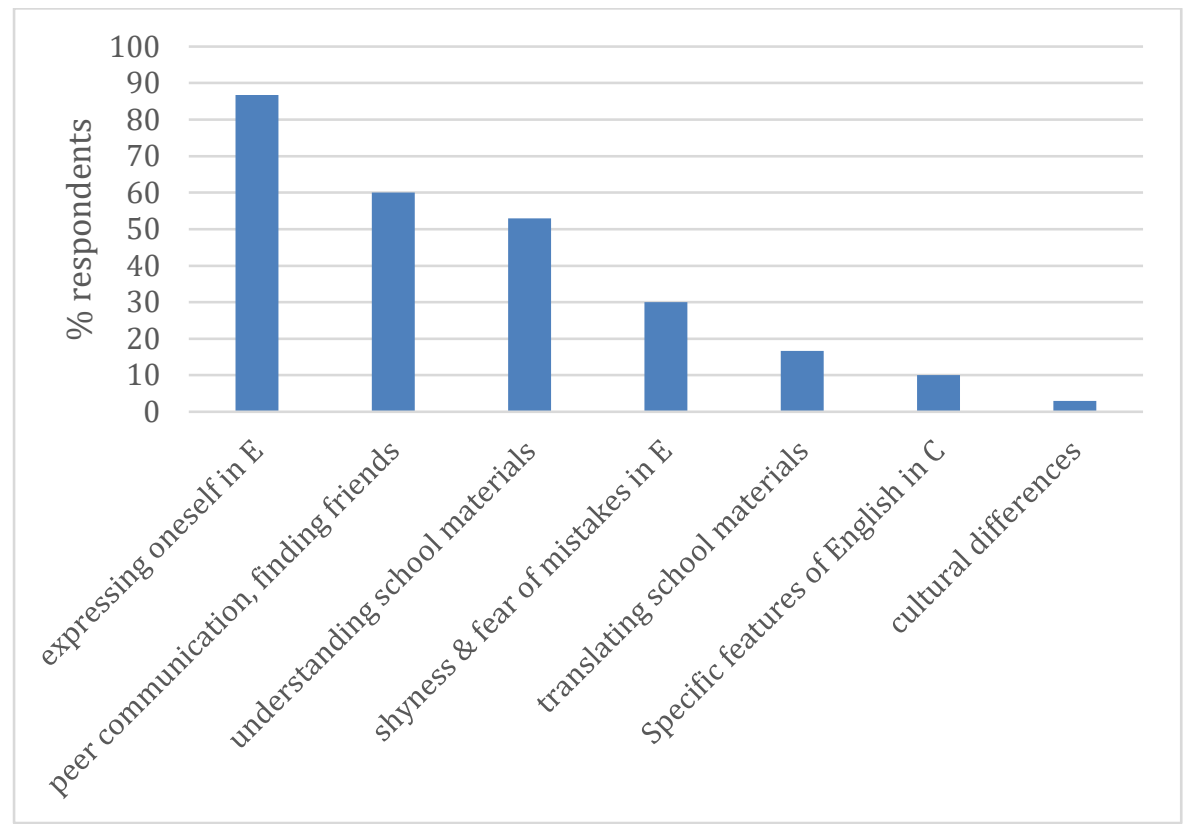

Expressing Themselves in English

As Figure 1 shows, the most frequent difficulty encountered by almost all (26 of 30,86.7\%) participants after their arrival in Canada was expressing themselves in English. Most Ukrainian immigrant youth took some English classes in Ukraine, but they did not acquire a basic conversational ability in English. Several participants reported that they remained silent at school during the first few weeks or months, or struggled to put together a few English words that they had learned at school in Ukraine (see example 1). One participant commented that she was frustrated by her inability to communicate; she attempted to talk with her teacher in Ukrainian, but the teacher could not understand what she said. Examples of participants' responses are provided below (F/M stands for female/male; the number refers to the age of the participant). 
Example 1:

The difficulties part for me was that I went to school and I did not know lots of words. I didn't understand like what the teacher said first, but then in four months I understood, but before the four months I could not understand anything $(\mathrm{F}, 8)$.

\section{Communicating with Peers and Finding New Friends}

The second most frequent difficulty outlined by Ukrainian immigrant youth $(18,60 \%)$ in their interviews was a problem with peer communication and finding new friends. The participants reported that Canadian born/raised youth did not want to interact, play, or make friends with them because Ukrainian immigrant youth did not understand English. A few participants observed that Canadian children sometimes were "shocked" to find out that a classmate did not speak English and could not understand that it was possible for a classmate to have no English-speaking ability. Some immigrant youth felt isolated because they could not understand their classmates and were too intimidated to talk in the new language.

\section{Example 2:}

When I just came here, there were like people that did not even like me. I actually had no friends up to two months I was here .... I have a lot of friends now $(\mathrm{M}, 12)$.

As a result of their inability to communicate with Canadian born/raised youth, Ukrainian youth socialized with each other, where possible. In the Ukrainian bilingual school, there were more children from Ukraine with whom they could make friends and communicate in Ukrainian (example 3). However, the participants who lived in suburban areas did not have this opportunity; four out of thirty participants indicated that there were no other Ukrainian immigrant students in their classes/schools; they stated that the lack of immigrant students made it particularly difficult for them to adjust to the new environment (example 4).

\section{Example 3:}

I have better friends, and it feels here like Ukraine now. All my friends are Ukrainians and only one friend, she is speaking English. Sometimes, I understand her and sometimes if not, she translates some words in Ukrainian $(F, 10)$. 
Example 4:

There is no one in my school to talk Ukrainian to because I am the only student from Ukraine in my school $(F, 14)$.

\section{Understanding School Materials and Subject Matter}

The third most commonly identified difficulty $(16,53 \%)$ for immigrant youth at school was understanding the subject matter and school materials (such as textbooks, handouts, assignment sheets). These difficulties related not only to English Arts, but also to mathematics, science, and other school subjects. The knowledge of mathematics and science by Ukrainian participants was above that of their Canadian peers due to school program differences between the countries, but they often could not understand the wordings of mathematical problems, the content of the school texts (such as science textbooks), and the teacher's explanations. Since understanding the subject matter was very hard for Ukrainian immigrant schoolchildren due to their low English proficiency, they reported trouble concentrating in class. Compared to native English speakers, Ukrainian immigrant youth needed more time to acquire enough English to comprehend the school textbooks. The result was that the Ukrainian immigrants fell behind the rest of the class and received low grades.

According to the participants' responses, these difficulties were not quite as severe for those who were enrolled in the Ukrainian bilingual schools, where they could study the subjects in Ukrainian. It was therefore easier for them to comprehend the subject information and the necessary school materials or find a teacher who spoke Ukrainian to explain something they did not understand (example 5). Twelve (60\%) of the twenty participants who attended regular English schools in Saskatchewan reported difficulties in comprehending the subject matter, whereas of the ten participants who attended the Ukrainian bilingual school, only three $(30 \%)$ reported encountering this difficulty.

Example 5:

I did not understand some questions, so I had to come to the teacher and ask again what it meant, and they explained it to me in Ukrainian (M, 13).

\section{Shyness and Fear of Making Mistakes while Speaking English}

Shyness and fear of making mistakes while speaking English was a less common problem. It was identified by nine $(30 \%)$ of the participants. The 
participants reported that although they knew that communication was important, due to their lack of confidence in their English skills, they felt stressed and were afraid to talk to their peers, their teachers, and outsiders for fear of making mistakes or mispronouncing words, or because their accent might be ridiculed (examples 6 and 7).

Example 6:

Mainly, like, older guys laughed at me, but now it doesn't happen $(M, 12)$. Example 7:

With strangers or, like, acquaintances, I don't really know what they talk about, so I just keep quiet $(F, 13)$.

\section{Translating School Subject Matter Back and Forth}

Four participants (16.7\%) reported having difficulties with translating school subject matter back and forth between English and Ukrainian in order to comprehend the subject matter (example 8). One participant indicated that he used his cell phone to translate.

Example 8:

I was translating every word into my language and then I was studying it in English, and then I was improving $(\mathrm{M}, 12)$.

Four youth participants who relied on translation of school subject matter from English to Ukrainian and back commented on how much time it took them. They had to spend two or three times more time learning the subject matter than the English-speaking children in their classes. The participants enrolled in the Ukrainian bilingual school had the advantage of getting assistance with translating some words, expressions, or texts from Ukrainian Canadian classmates or teaching assistants; this was particularly important for them in the first stages of ESL acquisition.

Specific Features of English Language Use Encountered by Participants in Canada

Three immigrant youth cited challenges related to specific features of English use encountered in Canada: (1) the use of academic language by teachers and teaching assistants; (2) the Canadian accent; (3) the use of slang and jokes; (4) a high speech rate and variable word choices (example 
9). One participant indicated that it was easier to communicate with other immigrant youth who spoke English as a second language because "they used not very difficult words," but "very simple ones."

Example 9:

They [Canadian peers of immigrant youth] use more slang, and sometimes I don't understand their accents $(\mathrm{M}, 14)$.

\section{Cultural Differences}

Adjustment to cultural difficulties was the least frequently identified problem with the participants' adjustment to life in Saskatchewan. It was mentioned by only one participant (3\%) (example 10). It is not clear whether this difference directly relates to the ESL problems described above.

Example 10:

Everything was new, and it took time to learn Canadian culture (F, 13).

Summary of Difficulties Immigrant Youth Faced in Adapting to a New School Environment

In addition to language-related problems (reported in Figure 1 and summarized above), three immigrant youths found the transition to a new school system to be stressful at first, as they did not know what to expect. However, soon after moving to Saskatchewan, they found the schooling system more relaxing and enjoyable than the schooling system in their home country; the number of home assignments was much less, and the teachers were more friendly. In sum, the immigrant youth reported that their low English-speaking proficiency made adaptation to the new society difficult; it limited their academic performance and made it harder to build new social networks and make friends with peers. Many of the immigrant youth experienced challenges at school and needed time to get used to the new environment and build the confidence to speak in the English language. Each immigrant youth tread an individual path in acquiring the new language. Immigrant youth enrolled in bilingual schools made the transition a little more smoothly than those attending regular schools. Some of the youth interviewed made positive comments about schoolteachers and other school personnel who tried to help them with their language barrier problems and spoke favourably about their experiences in ESL classes. 


\subsection{ESL SUPPORT AT SCHOOLS AND ITS ROLE IN PARTICIPANTS' ADAPTATION}

To help immigrant youth resolve the ESL-related difficulties summarized in section 4.1, most schools in Saskatchewan's urban areas provide support for immigrants in the form of classes that teach ESL. These classes are commonly organized to accommodate several schools, and the children attend the ESL classes at the providing school with professionally trained ESL teachers. Some schools have ESL specialists on staff.

Immigrant youth were asked the following questions. "Have you ever attended the ESL classes?" "Were the ESL classes helpful?" "In what way were the ESL classes helpful?" Responses to the interview questions are presented below. Twenty-two (73.3\%) of the thirty immigrant youth participants attended ESL classes to improve their English skills. Of these twenty-two participants, fourteen $(63.6 \%)$ indicated that the ESL classes were helpful in developing their English proficiency.

Example 11:

At school they had like... they had, like, a teacher that took me out and read with me in English and spoke with me. It did help very much (F, 10).

The development of English language skills by the participants was partly due to the ESL classes, partly due to the immersion in the English language environment, and partly due to the participants' own learning efforts. The immigrant youth interviewed testified that their new language skills helped to mitigate the negative language-related experiences that came with the adjustment to the new environment; i.e., they developed more confidence and social skills, built peer networks, made friends, got exposed to multiple cultures and traditions, and achieved higher grades and success in other spheres of their lives (example 12).

Example 12:

I can express myself more. When I know English, I can communicate with a lot of different people from different countries. They kind of open another world to, like, food, or, like, culture, traditions, so yeh, it is fun. You have like new way of meeting new friends 'cause you know English (M, 14). 
4.3 Immigrant Youth Participants' Motivation to Advance Their English SKILLS

Figure 2 shows the responses of the thirty participants to the interview question "What is the specific motivation for you to speak fluent English?" The top motivations of the Ukrainian immigrant participants to achieve better ESL skills were (1) finding a good job (22, 73.3\%), and (2) to acquire a higher education $(19,63.3 \%)$ (Figure 2$)$. The third most common motivation was communication and interaction with peers and friends (11, $36.7 \%$ ) (examples 13,14). One ten-year old girl responded that she wants to teach English to her children when she has them.

Example 13:

I think improving my English because then I will get like a better job and more friends to speak in English with $(M, 12)$.

Example 14:

My motivation is ... my future education. If I don't have English, I won't have an education (M, 14).

Figure 2. Motivation of immigrant youth participants to learn ESL.

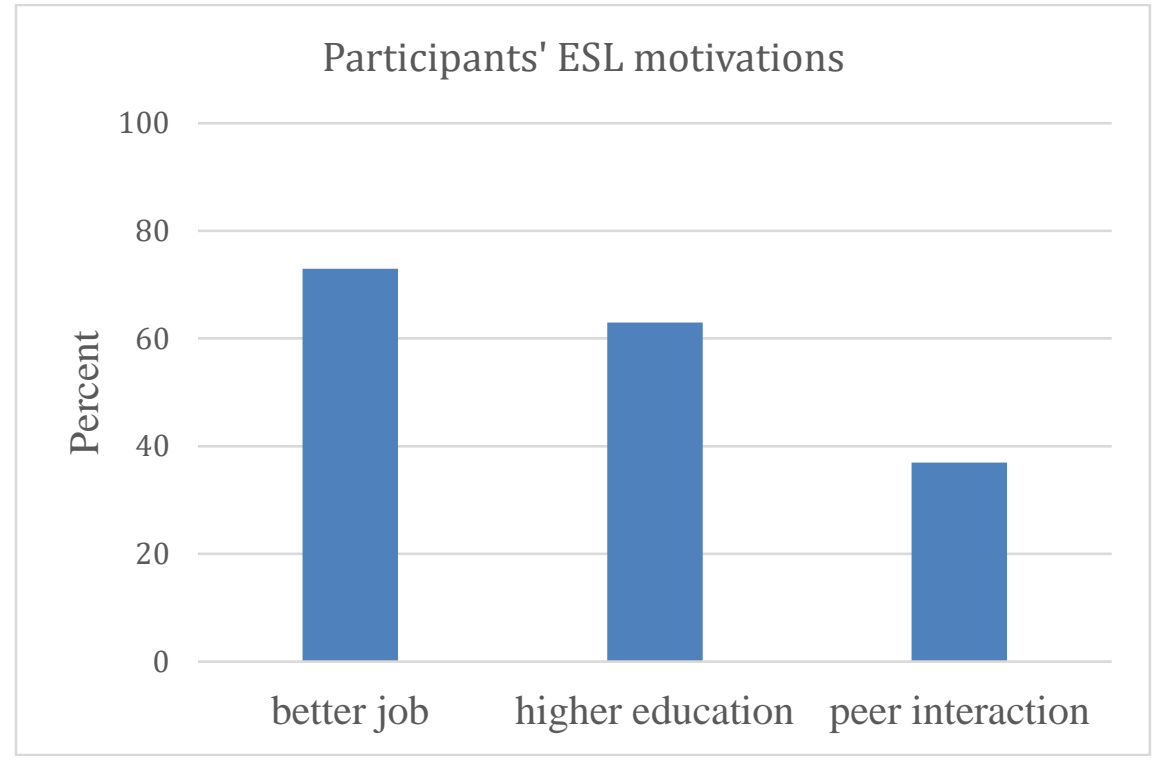


In summary, the interviews with immigrant youth demonstrate that, in Canada, most of them experienced difficulties expressing themselves in English, particularly in class, and many of them had problems understanding the subject matter and materials at school. Difficulties with English also affected their communication with peers and the ability to find friends. Some participants reported shyness, stress, and fear of making mistakes while speaking English. Spending too much time on translating school subject matter from English to Ukrainian was another, but less frequent, concern. The Canadian English language, cultural difficulties, and adapting to new school environments were named by one-three participants as difficulties they struggled with. Most participants found the ESL classes that were organized for them by the teachers helpful in overcoming their problems with communication in English.

\subsection{PARENTS' PERSPECTIVES}

Here we report an analysis of the data generated by answers to the questionnaire filled out by thirty parents of the Ukrainian immigrant youth that took part in this study (see section 3.1 for a description of the questionnaire). Parent responses were compared with Kruskal-Wallis $\mathrm{H}$ tests across the following parent subgroups. Parents of immigrant youth were grouped according to:

a) the age of their child ("parents of children" indicates parents of immigrant youth between 8-10 years old, and parents of immigrant youth 11-14 years old);

b) the duration of their (and their child's) stay in Canada ("shorter stay": under three years, "longer stay": over three years);

c) the level of English proficiency of immigrant youth: "higher E scores" refers to parents of children with higher ESL proficiency; "lower E scores" refers to parents whose children had lower levels of English proficiency; there were overall and by-skill groups (i.e., groups related to ESL proficiency in listening, speaking, and vocabulary);

d) the gender of the immigrant youth: female, male, other;

e) the age of the immigrant youth's arrival in Canada: "early arrival" (4-6 years old) and "late arrival" ( $7-13$ years old);

f) the type of school the immigrant youth attended (English or bilingual);

g) whose child attended or whose child did not attend ESL classes. 
Cases where a difference between parent groups was significant are described in the text.

4.4.1. Parents' Perspectives of the Importance of English Language Skills for Ukrainian Immigrant Youth

The Importance of ESL Skills for Acceptance in Canadian Society

Question 1 of the Questionnaire (Appendix 4, part B) asked parents: "How important is English for your child to be accepted in Canadian society?" Responses to this question were: crucial $(13,43.3 \%)$, very important $(10$, $33.4 \%)$, moderately important $(3,10 \%)$, slightly important $(4,13.3 \%)$; i.e., the majority $(77 \%)$ of parents believed that knowledge of the English language was of high importance for their children's acceptance in Canadian society. No respondents thought that knowing English was unimportant for their children. These responses are summarized in Figure 3.

Figure 3. Parents' opinions about the importance of English proficiency for an immigrant youth's acceptance in Canadian society.

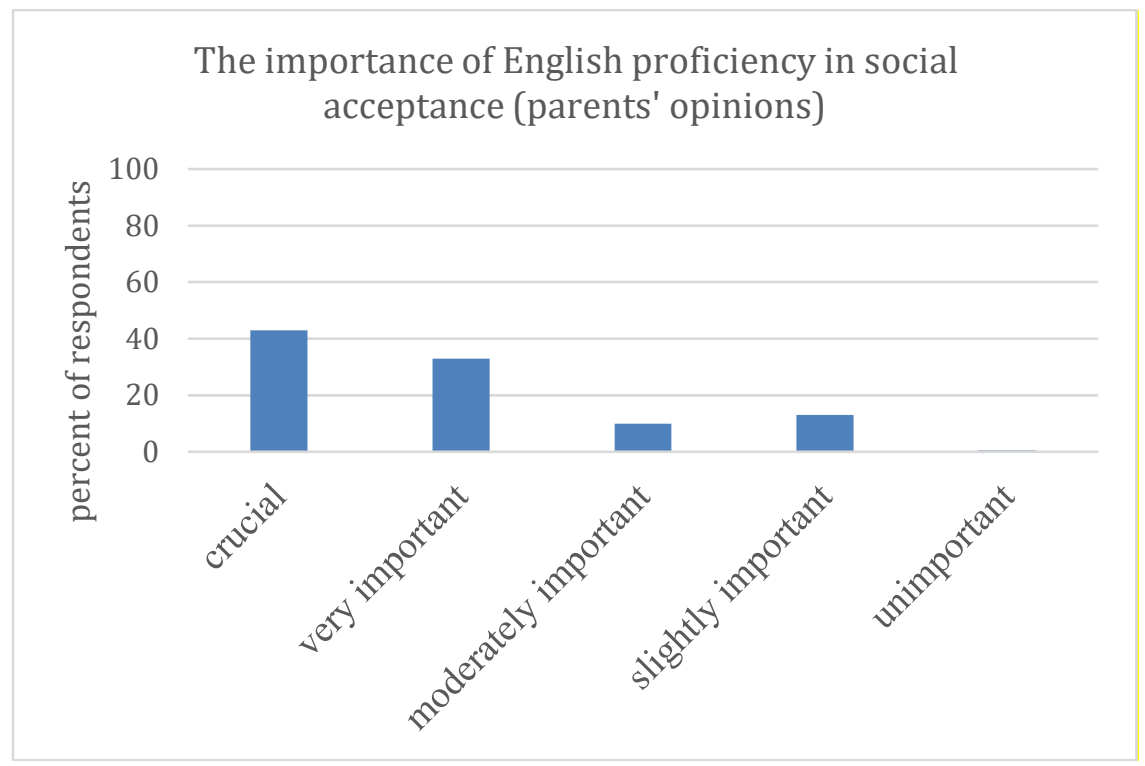


The Importance of ESL Skills for an Immigrant Youth's Successful Performance at School

Question 2 (Appendix 4 B) was "How important is English for your child's good performance at school?" The participants' answers were distributed as follows: crucial $(8,26.7 \%)$, very important $(21,70 \%)$, slightly important (1, $3.3 \%$ ), moderately important (0), unimportant (0) (Figure 4).

Figure 4. Parents' opinions regarding the importance of English proficiency in an immigrant youth's performance at school.

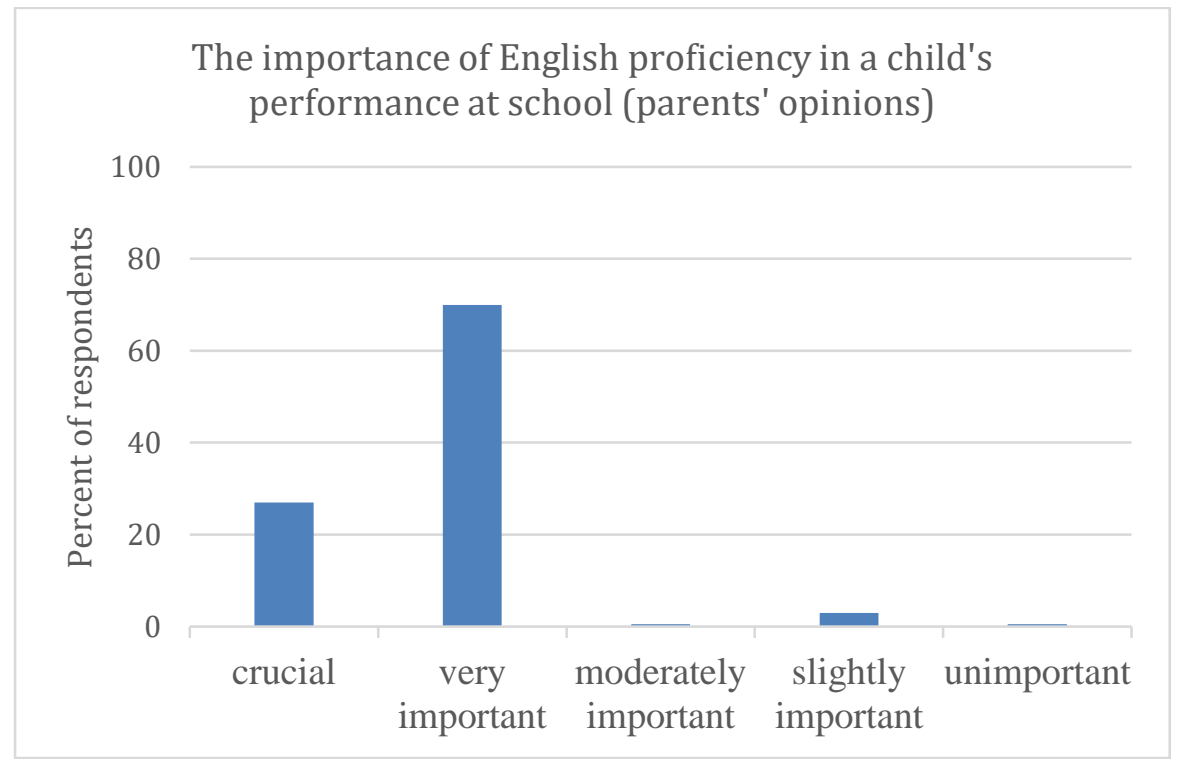

The Importance of ESL Skills in an immigrant youth's future career

Question 3 (Appendix 4 B) asked the parent respondents how important knowing English was for their child's future career. As shown in Figure 5, the parents thought that knowledge of the English language was either crucial $(19,63.3 \%)$ or very important $(11,36.7 \%)$ for their children's future careers. 
Figure 5. Parents' opinions about the importance of English proficiency in an immigrant youth's future career.

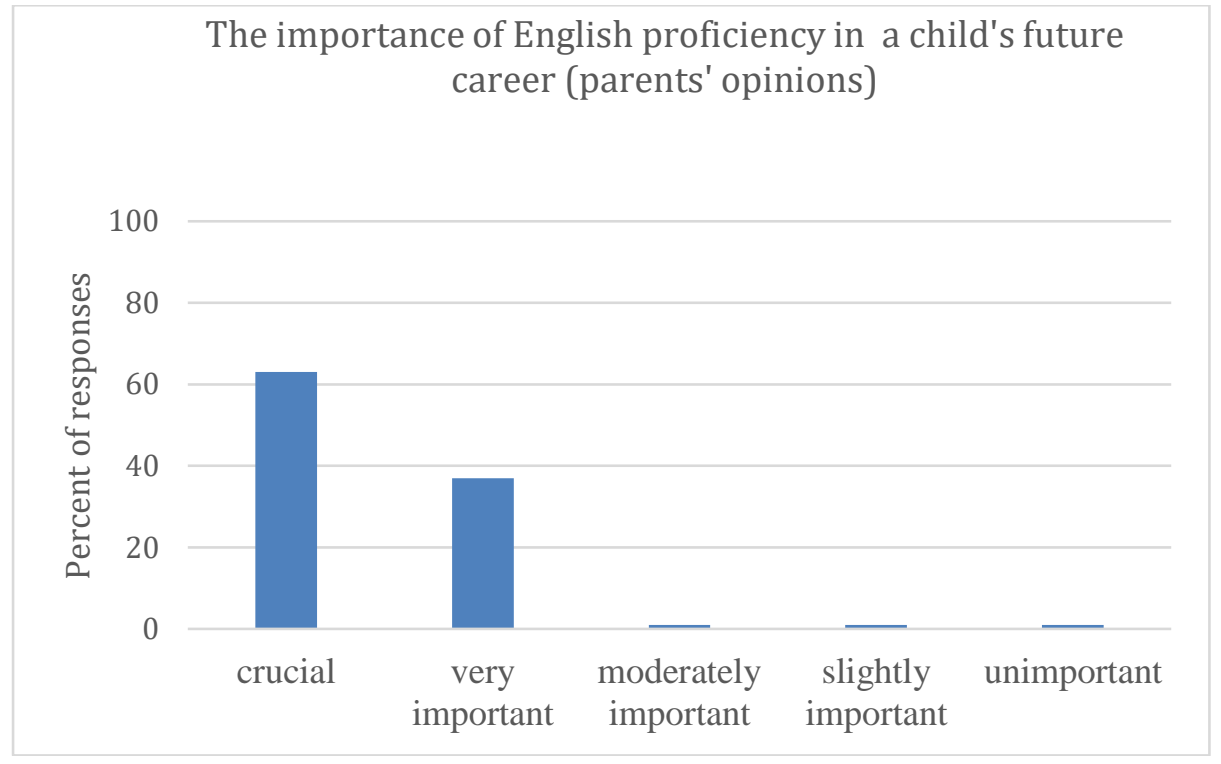

The Importance of ESL Skills in the Communication of Immigrant Youth with Friends and Peers

Question 4 (Appendix 4 B) asked respondents about the importance of knowing English in their children's communication with friends. Parents responded that ESL proficiency was crucial $(8,26.7 \%)$, very important (16, $53.3 \%)$, moderately important $(3,10 \%)$, and slightly important $(3,10 \%)$. 
Figure 6. Parents' opinions about the importance of English proficiency in their immigrant child's communication with peers and friends in Saskatchewan.

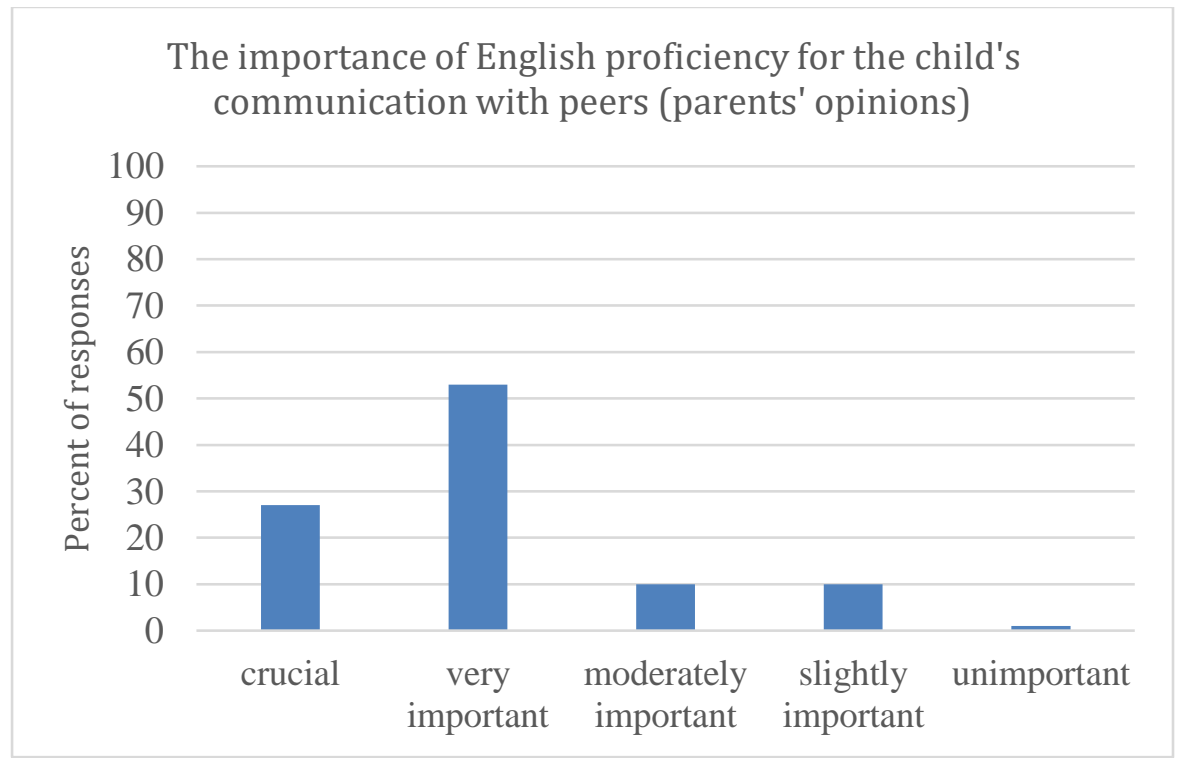

None of the above parameters related to the perceived importance of ESL skills (section 4.1) differed significantly among parent groups or correlated with any proficiency parameters. It appears that the importance to parents of their immigrant children's ESL skills is individual and has no direct connection to their children's ESL proficiencies or to their difficulties in immigration.

4.4.2. Adaptation Difficulties of Ukrainian Immigrant Youth Associated with the Level of English Proficiency, according to Their Parents

Difficulties with Making Friends

Parent responses to Question 5 (Appendix 4 B), concerning their immigrant child's difficulties with making friends due to limited ESL skills, were never $(11,36.7 \%)$, sometimes $(13,43.3 \%)$, and often $(13,43.3 \%)$ (Figure 7$)$. Significant differences were observed between the responses of parents who had children with higher English speaking proficiencies and the responses 
of parents who had children with lower English speaking proficiencies: $\mathrm{H}=21.6(1, \mathrm{~N}=30, \mathrm{p}<00001)$.

Figure 7. A summary of parents' responses to questions about ESLrelated difficulties experienced by their immigrant children.

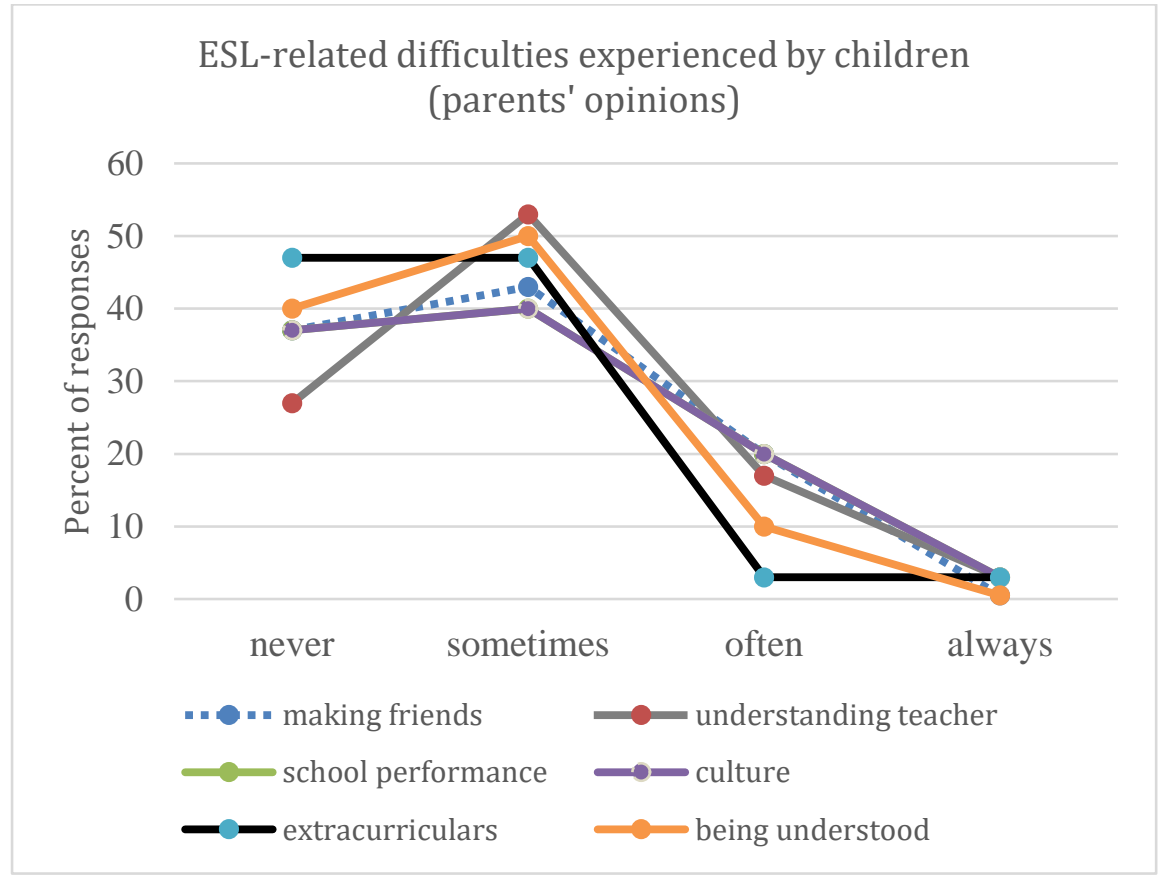

Difficulties Understanding Teachers' Instructions

When asked if limitations of English proficiency caused their immigrant children to experience difficulty in understanding a teacher's instructions, parents responded as follows: never $(8,26.7 \%)$, sometimes $(16,53.3 \%)$, often (5, 16.7\%), always (1,3.33\%). (Question 6, Appendix 4 B). Parents grouped according to the duration of their (and their child's) stay in Canada were asked if their immigrant children experienced difficulties understanding teachers' instructions. The responses of parents in the "shorter-stay" group were significantly different from the responses of parents in the "longer-stay" group: $H(1)=5.58, p=0.018$. According to the parents' responses, children who had been in Canada longer experienced difficulties understanding teachers' instructions less frequently. Another 
significant difference was observed between parents with children who had higher and lower English proficiencies, H (1)=7.86, p=0.005.

\section{Difficulties with Academic Performance}

Parents of immigrant youth were asked if their children experienced difficulty with academic performance due to their limited ESL proficiency. Parents responded as follows: never (11, 36.7\%), sometimes (12, 40\%), often (6, 20\%), and always (1,3.3\%) (Question 7, Appendix 4 B). A significant difference was observed between the responses of parents of youth with a shorter stay and the responses of parents of youth with a longer stay in Canada ( $H(1)=5.29, p=0.021)$, whereby a longer stay was associated with fewer difficulties. Other significant differences were observed between (1) responses of parents of youth with higher and lower ESL proficiencies (H (1) $=4.64, p=0.03$ ) and (2) between responses of parents of youth who had higher and lower speaking proficiencies $(\mathrm{H}(1)=6.95, \mathrm{p}=0.008)$.

\section{Difficulties Understanding Canadian Culture}

In Question 8 (Appendix 4 B), parents of immigrant youth were asked if the limited ESL skills of their children caused difficulty in understanding Canadian culture. The most frequent response to this question was sometimes $(15,40 \%)$, followed by never $(10,36.7 \%)$, often $(4,20 \%)$, and always (1, 3.3\%) (Figure 7). Parents of children who had stayed in Canada longer reported that their children had fewer difficulties with understanding Canadian culture than parents of children who had been in Canada a shorter time $(H(1)=5.29, p=0.21)$. Parents of children with better English skills $(H(1)=6.64, p=0.03)$ and with better speaking skills $(H(1)=6.95, p=0.008)$ reported that their children had difficulties with Canadian culture less frequently than the parents of children with weaker ESL and speaking skills.

\section{Difficulties with Extracurricular Activities}

In response to Question 9 (Appendix 4 B), parents described how often their children experienced ESL-related difficulties while attending extracurricular activities: never $(14,46.7 \%)$, sometimes $(14,46.7 \%)$, often $(1,3.33 \%)$, and always $(1,3.33 \%)$. The responses of parents of immigrant youth who had a shorter and longer stays in Canada were significantly different $(H(1)=10.46$, $\mathrm{p}=0.001$ ). Parents of children who had spent less time in Canada reported that their children had difficulties with extracurricular activities more often than the parents of youth who had been in Canada longer. Differences between the responses of the parents of youth who had arrived in Canada at younger or older ages were also observed $(H(1)=6.77, p=0.009)$ : i.e., with 
respect to extracurricular activities, youth who were older upon arrival in Canada had more difficulties than youth who were younger when they arrived in Canada. Children's English language speaking proficiency (H $(1)=7.62, p=0.005)$ and overall ESL proficiency $(H(1)=5.23, p=0.022)$ were factors in the reported difficulties with extracurricular activities.

\section{Difficulties Being Understood by Friends}

Parents' responses to Question 10 (Appendix $4 \mathrm{~B}$ ) that asked about the frequency of their child's difficulties with being understood by friends were split as follows: never $(12,40 \%)$, sometimes $(15,50 \%)$, and often $(3,10 \%)$. Parents of youth who had been in Canada longer reported fewer difficulties with their children being understood by friends than parents of youth who had been in Canada a shorter time ( $H(1)=5.01, p=0.025)$.

Overall, the responses of parents of immigrant youth indicate that immigrant youth experience multiple difficulties in Canada due to limited ESL proficiency. The parents of children with lower ESL speaking proficiency and lower overall ESL proficiency reported difficulties with adaptation to the new culture-particularly with making friends, understanding teachers' instructions, academic performance at school, understanding Canadian culture, and extracurricular activities. Differences in the duration of stay in Canada and the age of a child's arrival in Canada were perceived to affect the adaptation of youthful immigrants to the new Canadian environment. According to parents' responses, children/youth who arrived in Canada at an older age and had lived in the country for a shorter period of time experienced more difficulties with adaptation.

\subsubsection{Correlations between Parents' Perceptions of Children's ESL Difficulties and Children's ESL Proficiency}

Correlations between parents' responses to the questions describing their children's ESL-related adaptation difficulties and the ESL proficiency parameters of the immigrant youth are reported in Table 2 (significant correlations are highlighted). 
Table 2. Correlations between parents' responses to the questions about difficulties experienced by their immigrant children and the children's ESL scores.

\begin{tabular}{|c|c|c|c|c|c|}
\hline Question & $\begin{array}{l}\text { Type of } \\
\text { difficulty }\end{array}$ & Listening & Vocabulary/reading & Speaking & Overall \\
\hline 5 & finding friends & $\begin{array}{l}r=-0.17 \\
p=0.36\end{array}$ & $r=-0.03, p=0.87$ & $\begin{array}{l}r=-0.09 \\
p=0.62\end{array}$ & $\begin{array}{l}r=- \\
0.21 \\
p=0.26\end{array}$ \\
\hline 6 & $\begin{array}{l}\text { understanding } \\
\text { teacher }\end{array}$ & $\begin{array}{l}r=-0.15 \\
p=0.41\end{array}$ & $\mathrm{r}=-0.23, \mathrm{p}=0.20$ & $\begin{array}{l}r=-0.50 \\
p=0.005\end{array}$ & $\begin{array}{l}r=- \\
0.39 \\
p=0.03\end{array}$ \\
\hline 7 & $\begin{array}{l}\text { school } \\
\text { performance }\end{array}$ & $\begin{array}{l}r=-0.15 \\
p=0.41\end{array}$ & $r=-0.26, p=0.16$ & $\begin{array}{l}r=-0.40 \\
p=0.02\end{array}$ & $\begin{array}{l}r=- \\
0.35 \\
p=0.06\end{array}$ \\
\hline 8 & $\begin{array}{l}\text { Canadian } \\
\text { culture }\end{array}$ & $\begin{array}{l}r=-0.03 \\
p=0.86\end{array}$ & $r=-0.29, p=0.27$ & $\begin{array}{l}r=-0.39 \\
p=0.03\end{array}$ & $\begin{array}{l}r=- \\
0.29 \\
p=0.11\end{array}$ \\
\hline 9 & extracurriculars & $\begin{array}{l}r=0.20 \\
p=0.28\end{array}$ & $r=-0.37, p=0.04$ & $\begin{array}{l}r=-0.53 \\
p=0.002\end{array}$ & $\begin{array}{l}r=- \\
0.46, \\
p=0.01\end{array}$ \\
\hline 10 & $\begin{array}{l}\text { being } \\
\text { understood by } \\
\text { peers }\end{array}$ & $\begin{array}{l}r=-0.14 \\
p=0.46\end{array}$ & $r=-0.33, p=0.23$ & $\begin{array}{l}r=-0.50 \\
p=0.005\end{array}$ & $\begin{array}{l}r=- \\
0.38, \\
p=0.03\end{array}$ \\
\hline
\end{tabular}

The Pearson two-tail correlations reported in Table 2 indicate that parental perceptions of most of the adaptation difficulties experienced by their children correlate negatively (medium strength correlations) with the children's actual speaking proficiency skills. Overall, ESL proficiency correlates with three difficulties (finding friends, attending extracurricular activities, and being understood by peers). Knowledge of vocabulary correlates only with one parameter: "attending extracurricular activities." These results agree with the Kruskal-Wallis tests reported above and highlight the importance of speaking skills in preventing communicative and other adaptation difficulties.

\section{DISCUSSION}

In response to critiques of acculturation studies that claim that the specificities of contexts are overlooked (Chirkov), our research focuses on a specific group of immigrants (by age and by country of origin). It confirms earlier results that pointed out the utmost importance of language proficiency in the majority language for immigrants' adaptation in general 
(Andrade; Gonzales; Lam; McKay-Semmler and Kim) and for immigrant youth in Canada (Jia et al., "English Proficiency"; Lee and Chen; Portes). English language proficiency is indispensable for successful adaptation (acculturation) of immigrant youth in Saskatchewan (and in other Englishspeaking locations in Canada), since acculturation permeates most other aspects of adaptation, such as making friends and socializing (Jia et al., "English Proficiency"; Lee and Chen; Schleifer and Ngo).

Our study indicates that after relocation to Canada, Ukrainian immigrant youth experience a range of challenges connected with their level of English proficiency. Almost all (87\%) of the youth participants noted difficulties related to ESL proficiency upon arrival in Canada. The most frequent difficulties (named by at least 30\% of the immigrant youth studied) were expressing themselves in English, communicating with peers and finding friends, and understanding school materials and teachers' explanations. Similar to earlier research (Chiswick and Miller; Rumbaut; Fillmore), participants' insufficient knowledge of ESL resulted in shyness and a fear of making mistakes in L2.

The observations of immigrant youth participants were supported in the parents' responses to questions concerning the relationship between ESL skills and problems with understanding Canadian culture and difficulties being understood by friends. Earlier studies have demonstrated that ESL proficiency affects the adaptation of children and youth and particularly affects peer relationships and networks (Stodolska; Masgoret and Ward). Our study also demonstrated a connection between academic performance and ESL proficiency established in earlier studies (August and Hakuta), but only for the speaking skills. By reviewing parental reports we found that speaking skills are key elements in overcoming adaptation difficulties. It should be noted that the present study measured a "delayed" proficiency, a few years after immigration.

It is worth noting that some of the parents in our study appeared to underestimate the degree of ESL-related difficulties experienced by their children after immigration (between $27 \%$ and $48 \%$ of parental responses indicated that their children "never" had ESL difficulties).

The motivation for ESL acquisition of youth immigrants in our study was very high and overwhelmingly pragmatic (Dörnyei 65): they learned English to get a better job, a higher education, and to improve interaction with peers. These sentiments are echoed in their parents' responses. The majority of the parents interviewed believed that ESL learning is very important for or crucial to the performance of immigrant youth at school, their future careers, their communication with peers, and their acceptance in Canadian society. These results are not surprising, as earlier studies have found that immigrant children and adolescents are more highly motivated academically than their Canadian peers (Areepattamannil and Freeman). 
Our study also supports the importance of the following factors in adaptation of children and youth: duration of stay in Canada and age upon arrival. In congruence with earlier research (Stevens), our results suggest that difficulties in understanding teacher instructions and difficulties in following extracurricular activities are more severe among immigrant youth who have lived in Canada for a shorter period of time compared to immigrant youth who have lived in Canada for a longer time (as reported by parents). Age upon arrival in Canada was only significant for immigrant youth who had difficulties with extracurricular activities (as reported by parents). Immigrant youth who arrived in Saskatchewan at an earlier age were reported to have difficulties with extracurricular activities less frequently than immigrant youth who arrived in Saskatchewan at a later age. Such relevance to immigrant youth adaptation of (1) time spent in a new country and (2) age upon arrival in a new country have been reported in earlier studies (Fry; Stevens).

\section{Limitations of the Study and Directions for Future Research}

The study was limited by the sample size (the location offered a relatively small population) and by lack of funding, so the results cannot be generalized. The small sample size limited possibilities for statistical analysis. Further research could address a larger sample in more diverse locations.

The ESL proficiency of the immigrant youth was measured at the time of the study, whereas the initial ESL proficiency of the immigrant youth upon entering Canada would likely have had a much stronger predictive power for the adaptation to Saskatchewan of Ukrainian immigrant youth. A longitudinal study of immigrant children/youth adaptation with repeated measures of ESL proficiency and adaptation difficulties could resolve this limitation in the future.

Apart from the language proficiencies of immigrant youth, we present quantitative data from parental responses regarding the adaptation to Saskatchewan of their immigrant offspring. However, parents' awareness of their children's adaptation difficulties is likely limited. Moreover, our study did not consider the home country language, culture retention, family policies, family health, and other aspects of immigrant youth adaptation (Lam).

Due to the small sample size, some factors that we analyzed (in particular, gender, age, school type) were not found to be significant to the adaptation of Ukrainian youth to life in Saskatchewan. In particular, school type did not appear to be significant in parental responses, possibly because only ten immigrant youth participants attended Ukrainian bilingual school 
(vs. twenty immigrant youth participants who attended schools with English as the sole language of instruction). It is possible that the parents of the immigrant youth studied were not fully aware of the different experiences that children have in Canadian English-language-only schools and Canadian Ukrainian bilingual schools, or the parents might have had general misconceptions of bilingual schools. Some parents reported skepticism of bilingual schools and expressed a belief that the ESL progress would be faster in a full immersion context (similarly to Lee's findings). However, applied linguistic research has shown that including immigrants' native language in educational contexts has multiple positive benefits in the adaptation of immigrants to a new language (Bialystok; Lindholm-Leary). The importance of school type is affirmed in the qualitative part of the present study in the interviews with young immigrant participants. Their adaptation experiences were less traumatic and more positive due to the additional help with assignments, materials, and English vocabulary and grammar that they received from other children and teachers/TAs who spoke Ukrainian. This point, however, needs to be confirmed in future studies. A more focused comparison of parental beliefs about the benefits of one school type over another and their children's experiences in monolingual English vis-s-vis Ukrainian bilingual schools could clarify the significance of the "school type" factor.

About $73 \%$ of the participants in our study took ESL classes in Canada. Of these, $66 \%$ indicated that these classes were helpful. Earlier studies reported unsuccessful experiences of immigrant youth with ESL classes (Stodolska), attributing the unsuccessful experiences to the learning climate and the quality of teaching in the ESL classes (Portes and Rumbaut). We have no evidence to interpret the level of satisfaction of Ukrainian immigrant participants with their ESL courses. The ESL experiences of different groups of immigrant youth would be an interesting new direction to explore.

Our study also suggests some differences between the responses of immigrant youth and the responses of their parents regarding their perception of the youth's adaptation process. First, the parents seem to underestimate the amount of adaptation difficulties faced by their children. Second, immigrant youth responses do not show many concerns regarding the understanding of Canadian culture, whereas $63 \%$ of parents responded that their children had difficulties understanding Canadian culture. It would be interesting to pursue these differences in future studies. 


\section{CONCLUSION}

As the government of Canada attempts to divert the immigrant flow from major cities to other areas of the country (Ferrer et al.), investigations of immigrants' adaptation in less populated areas are increasingly more pertinent. The successful adaptation of immigrants and refugees necessitates an integrative role of ESL skills (Lam). The growing cohort of youthful immigrants has a high potential for successful integration in the Canadian society if the concerns and needs and special vulnerabilities of this cohort are addressed (Yang).

Our interviews with Ukrainian immigrant youth indicated that they had very limited English proficiency upon their arrival in Canada, and their inability to communicate negatively affected their adaptation to the new country. Immigrant youth reported that upon their arrival in Canada, they had limited ability to express themselves in English, to communicate with peers, and to find friends. They had difficulty understanding school materials and teachers' explanations. They were afraid of making mistakes and were too shy to ask for help in L2. Here we show that ESL-related adaptation difficulties of the immigrant youths' (reported by parents) are connected with the time they have spent in Canada, their age upon arrival, and their overall English proficiency. In our interviews with Ukrainian immigrant youth, the subjects professed a motivation to learn English so they would be able to communicate with peers, and eventually to get a better job or receive a higher education. Although the results are preliminary rather than definitive due to the small sample size, in terms of potential applications, our study highlights the importance of ESL skills in the adaptation of immigrant children and youth in Saskatchewan. 


\section{Works Cited}

"About Ukrainians: Ukrainians in Saskatchewan." Ukrainian Canadian CongressSaskatchewan Provincial Council, 2020, http://ucc.sk.ca/about/ukrainians-insk. Accessed on 7 July 2020.

Andrade, Maureen Snow. "International Students in English-Speaking Universities." Journal of Research in International Education, vol. 5, no. 2, 2006, pp. 131-54. DOI: $10.1177 / 1475240906065589$.

Areepattamannil, Shalijan, and John G. Freeman. "Academic Achievement, Academic Self-Concept and Academic Motivation of Immigrant Adolescents in the Greater Toronto Area Secondary Schools." Journal of Advanced Academics, vol. 19, no. 4, 2008, pp. 700-43. DOI: 10.4219/jaa-2008-831.

Ashworth, Mary. "The Cultural Adjustment of Immigrant Children in Canada." Uprooting and Surviving: Adaptation and Resettlement of Migrant Families and Children, edited by Richard C. Nann, Springer, 1975, pp. 77-83.

August, Diane, and Kenji Hakuta, editors. Improving Schooling for Language-Minority Children: A Research Agenda. National Academy P, 1997.

Berry, John W. "Acculturation: Living Successfully in Two Cultures." International Journal of Intercultural Relations, vol. 29, no. 6, Nov. 2005, pp. 697-712. DOI: 10.1016/j.ijintrel.2005.07.013.

---. "Conceptual Approaches to Acculturation." Acculturation: Advances in Theory, Measurement, and Applied Research, edited by Kevin M. Chun et al., American Psychological Association, 2003, pp. 17-37.

Berry, John W. et al. "Immigrant Youth: Acculturation, Identity, and Adaptation." Applied Psychology: An International Review, vol. 55, no. 3, 2006, pp. 303-32.

Bialystok, Ellen. "Bilingual Education for Young Children: Review of the Effects and Consequences." International Journal of Bilingual Education and Bilingualism, vol. 21, no. 6, 2018, pp. 666-79. DOI: 10.1080/13670050.2016.1203859.

“Canada's Population Clock (Real-Time Model)." Statistics Canada, 2019, https://www150.statcan.gc.ca/n1/pub/71-607-x/71-607-x2018005-eng.htm. Accessed 19 Dec. 2020.

Carballo, Manuel. Scientific Consultation on the Social and Health Impact of Migration: Priorities for Research. International Organization for Migration, 1994.

Cheung, Benjamin Y. et al. "Evidence for a Sensitive Period for Acculturation: Younger Immigrants Report Acculturating at a Faster Rate." Psychological Science, vol. 22, no. 2, 2011, pp. 147-52. DOI: 10.1177/0956797610394661.

Chirkov, Valery. "Critical Psychology of Acculturation: What Do We Study and How Do We Study It When We Investigate Acculturation?" International Journal of Intercultural Relations, vol. 33, no, 2, 2009, pp. 94-105. DOI: 10.1016/j.ijintrel.2008.12.004.

Chiswick, Barry R., and Paul W. Miller. The Economics of Language: International Analysis. Routledge, 2007.

Collier, Virginia P. "Age and Rate of Acquisition of Second Language for Academic Purposes." TESOL Quarterly, vol. 21, no. 4, 1987, pp. 617-41. DOI: $10.2307 / 3586986$. 
Culhane, Stephen F. "An Intercultural Interaction Model: Acculturation Attitudes in Second Language Acquisition." Electronic Journal of Foreign Language Teaching, vol. 1, no. 1, 2004, pp. 50-61.

Denis, Wilfrid. "Language in Saskatchewan." Language in Canada, edited by John Edwards, Cambridge UP, 1998, pp. 425-41.

Dörnyei, Zoltan. Teaching and Researching Motivation. Longman, 2001.

Duffin, Erin. "Number of Recent Immigrants in Saskatchewan from 2000 to 2019." Statista, 2019, https://www.statista.com/statistics/609178/number-ofimmigrants-in-saskatchewan/. Accessed 21 Dec. 2020.

Edmonston, Barry. "Canadian Immigration Trends and Patterns." Canadian Studies in Population, vol. 43, nos. 1-2, Spring/Summer 2016, pp. 78-116. DOI: $10.25336 /$ P64609.

Erlingsson, Christen, and Petra Brysiewicz. "A Hands-on Guide to Doing Content Analysis." African Journal of Emergency Medicine, vol. 7, no. 3, 2017, pp. 93-99. DOI: $10.1016 /$ j.afjem.2017.08.001.

Feliciano, Cynthia. "Does Selective Migration Matter? Explaining Ethnic Disparities in Educational Attainment among Immigrants' Children." International Migration Review, vol. 39, no. 4, Winter 2005, pp. 841-71. DOI: 10.1111/j.17477379.2005.tb00291.x.

Ferguson, Gail M., and Marc H. Bornstein. "Tridimensional (3D) Acculturation: Culture and Adaptation of Black Caribbean Immigrants in the United States." Global Perspectives on Well-being in Immigrant Families, edited by Radosveta Dimitrova et al., Springer, 2014, pp. 31-51.

Fernandez-Kelly, Patricia. "The Integration Paradox: Contrasting Patterns in Adaptation among Immigrant Children in Central New Jersey." Ethnic and Racial Studies, vol. 43, no. 1, Jan. 2020, pp. 180-98. DOI: 10.1080/01419870.2019.1667510.

Ferrer, Ana, et al. "New Directions in Immigration Policy: Canada's Evolving Approach to the Selection of Economic Immigrants." International Migration Review, vol. 48, no. 3, Fall 2014, pp. 846-67. DOI: 10.1111/imre.12121.

Fillmore, Lily Wong. "Language Minority Students and School Participation: What Kind of English Is Needed?" Journal of Education, vol. 164, no. 2, May 1982, pp. 143-56. DOI: $10.1177 / 002205748216400204$.

"Focus on Geography Series, 2016 Census." Statistics Canada, 2017, https://www12.statcan.gc.ca/census-recensement/2016/as-sa/fogsspg/Facts-pr-eng.cfm?LANG=Eng\&GK=PR\&GC=47\&TOPIC=7. Accessed 19 Dec. 2020.

Fry, Richard. "Are Immigrant Youth Faring Better in US Schools?" International Migration Review, vol. 41, no. 3, Fall 2007, pp. 579-601. DOI: 10.1111/j.17477379.2007.00086.x.

Glozman, Jenny, and Susan. S. Chuang. "Multidimensional Acculturation and Identity of Russian-Speaking Youth in Canada: The Role of Parents." Journal of Adolescent Research, vol. 34, no. 4, 2019, pp. 464-88.

Goh, Christine. "Metacognitive Instruction for Second Language Listening Development: Theory, Practice and Research Implications." RELC Journal, vol. 39, no. 2, Aug. 2008, pp. 188-213. DOI: 10.1177/0033688208092184. 
Gonzales, Jarren Thomas. The Acculturation Experience of International Graduate Students: A Qualitative Investigation. 2006. University of Notre Dame, PhD dissertation.

Hakuta, Kenji, et al. "Critical Evidence: A Test of the Critical Period Hypothesis for Second-language Acquisition." Psychological Science, vol. 14, no. 1, Jan. 2003, pp. 31-38. DOI: 10.1111/1467-9280.01415.

Halko-Addley, Ashley, and Natalia Khanenko-Friesen. "Language Use and Language Attitude of Ukrainian Canadians on the Prairies: An Ethnographic Analysis." East/West: Journal of Ukrainian Studies, vol. 6, no. 2, 2019, pp. 53-71. DOI: 10.21226/ewjus530.

Indefrey, Peter. "A Meta-Analysis of Hemodynamic Studies on First and Second Language Processing: Which Suggested Differences Can We Trust and What Do They Mean?" Language Learning, vol. 56, no. 1, July 2006, pp. 279-304. DOI: 10.1111/j.1467-9922.2006.00365.x.

Isajiw, Wsevolod. "The Ukrainian Diaspora." The Call of the Homeland: Diaspora Nationalisms, Past and Present, edited by Allon Gal et al., Brill, 2010, pp. 289-322.

Jia, Fanli, et al. "English Proficiency and Acculturation among Chinese Immigrant Youth in Canada: A Reciprocal Relationship." Journal of Multilingual and Multicultural Development, vol. 37, no. 8, Nov. 2016, pp. 774-82. DOI: 10.1080/01434632.2015.1133630.

Jia, Gisela, et al. "Long-term Language Attainment of Bilingual Immigrants: Predictive Variables and Language Group Differences." Applied Psycholinguistics, vol. 23, no. 4, December 2002, pp. 599-621. DOI: 10.1017/S0142716402004058.

Juang, Linda P., and Moin Syed. "The Evolution of Acculturation and Development Models for Understanding Immigrant Children and Youth Adjustment." Child Development Perspectives, vol. 13, no. 4, Dec. 2019, pp. 241-46. DOI: 10.1111/cdep.12346.

Klymasz, Robert B. "Culture Maintenance and the Ukrainian Experience in Western Canada." New Soil-Old Roots: The Ukrainian Experience in Canada, edited by Jaroslav Rozumnyj, Ukrainian Academy of Arts and Sciences in Canada, 1 Jan. 1983, pp. 173-83.

Kordan, Bohdan Stephan. Ukrainian Canadians and the Canada Census, 1981-1996. Heritage Press, 2000.

Kostyuk, Serhiy. Canada and Saskatchewan through Their Eyes: 2007 Survey of Recent Immigrants from Ukraine: Analytical Report. Sergius Press, 2007.

Lam, Michelle. "Language Education for Newcomers in Rural Canada: Needs, Opportunities and Innovation." Journal of Rural and Community Development, vol. 14, no. 1, 19 Mar. 2019, pp. 77-97.

Lee, Betty Kaman, and Ling Chen. "Cultural Communication Competence and Psychological Adjustment: A Study of Chinese Immigrant Children's CrossCultural Adaptation in Canada." Communication Research, vol. 27, no. 6, Dec. 2000, pp. 764-92. DOI: 10.1177/009365000027006004.

Lee, Stacey. Up against Whiteness: Race, School, and Immigrant Youth. Teachers College P, 2005.

Lehr, John C. "Peopling the Prairies with Ukrainians." Canada's Ukrainians: Negotiating an Identity, edited by Lubomyr Luciuk and Stella Hryniuk, U of Toronto P, 1991, pp. 30-53. 
"Levels Test (Recognition)." lextutor.ca, 2016, https://www.lextutor.ca/tests/levels/recognition/1k/test 1.html. Accessed 1 Oct. 2019.

Lindholm-Leary, Kathryn J. Dual Language Education. Multilingual Matters, 2001.

Lynch, Tony, and David Mendelsohn. "Listening." Introduction to Applied Linguistics, edited by Norbert Schmitt, Arnold, 2010, pp. 181-96.

Makarova, Veronika, and Khrystyna Hudyma. "Ukrainian Ethnicity and Language Interactions in Saskatchewan." The Ukrainian Canadians, special issue of Canadian Ethnic Studies, vol. 47, nos. 4-5, 2015, pp. 85-109. DOI: 10.1353/ces.2015.0054.

Makarova, Veronika, et al. “Children's Language Exposure and Parental Language Attitudes in Russian-as-a-Heritage-Language Acquisition by Bilingual and Multilingual Children in Canada." International Journal of Bilingualism, vol. 23, no. 2, Apr. 2019, pp. 457-85. DOI: 10.1177/1367006917740058.

Masgoret, Anne-Marie, and Colleen Ward. "Culture Learning Approach to Acculturation." The Cambridge Handbook of Acculturation Psychology, edited by David L. Sam and John W. Berry, Cambridge UP, 2006, pp. 58-77.

McKay-Semmler, Kelly, and Young Yun Kim. "Cross-Cultural Adaptation of Hispanic Youth: A Study of Communication Patterns, Functional Fitness, and Psychological Health." Communication Monographs, vol. 81, no. 2, June 2014, pp. 133-56. DOI: 10.1080/03637751.2013.870346.

Mendes, Maria Manuela. "Representations about Discrimination Practices in the Education System Built by Russian and Ukrainian Immigrants' Children in Lisbon Metropolitan Area." Trames: A Journal of the Humanities and Social Sciences, vol. 13, no. 4, 2009, pp. 341-56. DOI: 10.3176/tr.2009.4.02.

Mouzitchka, Victoria. An Insight into the Lives of Successful Ukrainian Immigrant Students in Ontario. 2006. Queen's University, PhD dissertation.

Moyer, Alene. Age, Accent and Experience in Second Language Acquisition: An Integrated Approach to Critical Period Inquiry. Multilingual Matters, 2004. Second Language Acquisition 7.

Páez, Mariela M. "Predictors of English-Language Proficiency Among Immigrant Youth." Bilingual Research Journal, vol. 32, no. 2, 2009, pp. 168-87. DOI: $10.1080 / 15235880903170017$.

Perez, Rose M. "Linguistic Acculturation and Context on Self-Esteem: Hispanic Youth between Cultures." Child and Adolescent Social Work Journal, vol. 28, no. 3, June 2011, pp. 203-28. DOI: 10.1007/s10560-011-0228-y.

Perreira, Krista M., et al. "Integrating Hispanic Youth: Perspectives from White and Black Americans in Emerging Hispanic Communities and Schools." Ethnic and Racial Studies, vol. 43, no. 1, Jan. 2020, pp. 119-41. DOI: 10.1080/01419870.2019.1667512.

Portes, Alejandro, and Rubén Rumbaut. Legacies: The Story of the Immigrant Second Generation. U of California P, 2001.

Portes, Pedro R. "Social and Psychological Factors in the Academic Achievement of Children of Immigrants: A Cultural History Puzzle." American Educational Research Journal, vol. 36, no. 3, Fall 1999, pp. 489-507. DOI: 10.3102/00028312036003489. 
Portes, Pedro R., and Madelon Zady. "Self-Esteem in the Adaptation of SpanishSpeaking Adolescents: The Role of Immigration, Family, Conflict, and Depression." Hispanic Journal of Behavioral Sciences, vol. 24, no. 3, Aug. 2002, pp. 296-318. DOI: $10.1177 / 0739986302024003003$.

Roberts, Robert E., and Yuan-Who Chen. "Depressive Symptoms and Suicidal Ideation among Mexican-Origin and Anglo Adolescents." Journal of the American Academy of Child and Adolescent Psychiatry, vol. 34, no. 1, Jan. 1995, pp. 81-90. DOI: 10.1097/00004583-199501000-00018.

Rumbaut, Rubén G. "The Crucible within: Ethnic Identity, Self-Esteem, and Segmented Assimilation among Children of Immigrants." International Migration Review, vol. 28, no. 4, Winter 1994, pp. 748-94. DOI: $10.2307 / 2547157$.

Schleifer, Barbara, and Hieu Ngo. "Immigrant Children and Youth in Focus." Canadian Issues, Spring 2005, pp. 29-33.

Searle, Wendy, and Colleen Ward. "The Prediction of Psychological and Sociocultural Adjustment during Cross-Cultural Transitions." International Journal of Intercultural Relations, vol. 14, no. 4, 1990, pp. 449-64. DOI: 10.1016/01471767(90)90030-Z.

Short, Deborah J., and Shannon Fitzsimmons. Double the Work: Challenges and Solutions to Acquiring Language and Academic Literacy for Adolescent English Language Learners. A Report to Carnegie Corporation of New York. The Alliance for Excellent Education, 2007.

Stevens, Gillian. "Trajectories of English Acquisition among Foreign-Born SpanishLanguage Children in the United States." International Migration Review, vol. 49, no. 4, Winter 2015, pp. 981-1000. DOI: 10.1111/imre.12119.

Stiefel, Leanna, et al. "Age of Entry and the High School Performance of Immigrant Youth." Journal of Urban Economics, vol. 67, no. 3, May 2010, pp. 303-14. DOI: 10.1016/j.jue.2009.10.001.

Stodolska, Monika. "Adaptation Problems among Adolescent Immigrants from Korea, Mexico and Poland." Journal of Immigrant \& Refugee Studies, vol. 6, no. 2, 2008, pp. 197-229. DOI: 10.1080/15362940802198884.

Tavares, Antonio. "From Heritage to International Languages: Globalism and Western Canadian Trends in Heritage Language Education." Canadian Ethnic Studies, vol. 32, no. 1, 2000, pp. 156-71.

"Test Your Listening." Crowdsignal.com, 2016, english.polldaddy.com/s/test-your-listening-3-6-

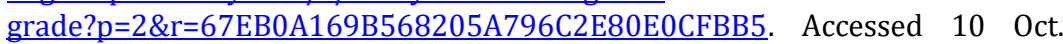
2020.

Thompson, Marilyn S. et al. “Exito en California? A Validity Critique of Language Program Evaluations and Analysis of English Learner Test Scores." Education Policy Analysis Archives, vol. 10, no. 7, 25 Jan. 2002, pp. 1-48.

Turcotte, Martin. "Education and Labour Market Outcomes of Children with an Immigrant Background by Their Region of Origin." Statistics Canada, 15 Nov. 2019, https://www150.statcan.gc.ca/n1/pub/89-657-x/89-657-x2019018eng.htm. Accessed 21 Dec. 2020. 
"Ukrainian Immigrants to Canada." The Canadian Magazine of Immigration, 15 Aug. 2019, https://canadaimmigrants.com/ukrainian-immigrants-canada/. Accessed 21 Dec. 2020.

Ward, Colleen. "Acculturation." Handbook of Intercultural Training, edited by Dan Landis and Rabi S. Bhagat, Sage, 1996, pp. 124-47.

Ward, Colleen, and Nicolas Geeraert. "Advancing Acculturation Theory and Research: The Acculturation Process in Its Ecological Context." Current Opinion in Psychology, vol. 8, Apr. 2016, pp. 98-104. DOI: 10.1016/j.copsyc.2015.09.021.

Ward, Colleen, and Antony Kennedy. "Acculturation Strategies, Psychological Adjustment, and Sociocultural Competence during Cross-Cultural Transitions." International Journal of Intercultural Relations, vol. 18, no. 3, Summer 1994, pp. 329-343. DOI:10.1016/0147-1767(94)90036-1.

---. "The Measurement of Sociocultural Adaptation." Theory and Research on Intercultural Relations, special issue of International Journal of Intercultural Relations, vol. 23, no. 4, Aug. 1999, pp. 659-677. DOI:10.1016/S01471767(99)00014-0.

Wilson, Jessie, et al. "Beyond Culture Learning Theory: What Can Personality Tell Us about Cultural Competence?" Journal of Cross-Cultural Psychology, vol. 44, no. 6, Aug. 2013, pp. 900-27. DOI: 10.1177/0022022113492889.

Xue, Li. Portrait of an Integration Process: Difficulties Encountered and Resources Relied on by Newcomers in Their First Four Years in Canada. Citizenship and Immigration Canada, June 2007, http://www.cic.gc.ca/english/pdf/researchstats/portrait-integr-process-e.pdf. Accessed on 19 Dec. 2019.

Yang, Fei-Ju. "Is Childhood Migration a Mental Health Risk? Exploring Health Behaviors and Psychosocial Resources As Pathways Using the Cross-Sectional Canadian Community Health Survey." Social Science Research, vol. 83, Sept. 2019. DOI: 10.1016/j.ssresearch.2019.04.016.

Yeh, Christine J. et al. "The Cultural Adjustment and Mental Health of Japanese Immigrant Youth." Adolescence, vol. 38, no. 151, Fall 2003, pp. 481-500.

Yosso, Tara J. "Whose Culture Has Capital? A Critical Race Theory Discussion of Community Cultural Wealth." Race, Ethnicity and Education, vol. 8, no. 1, Mar. 2005, pp. 69-91. DOI: 10.1080/1361332052000341006.

$\mathrm{Yu}$, Stella M. et al. "Acculturation and the Health and Well-Being of U.S. Immigrant Adolescents." Journal of Adolescent Health, vol. 33, no. 6, Dec. 2003, pp. 479-88. DOI: 10.1016/S1054-139X(03)00210-6.

Zahar, Rick, et al. "Acquiring Vocabulary through Reading: Effects of Frequency and Contextual Richness." The Canadian Modern Language Review, vol. 57, no. 4, June 2001, pp. 541-65. DOI: 10.3138/cmlr.57.4.541. 


\section{APPENDIX 1}

Listening Test Questions

1. Dogs are man's ........ friend.

- Better

- Best

- Good

2. A cat may one day ........... the house.

- Leave

- Stay in

- Forget

3. Dogs guard the house from

- Friends

- People

- Thieves

4. They can bring you your

- Supper

- Slippers

- Blanket

5. Dogs tell lies.

- Never

- Always

- Often

6. Touching them is

- Relaxing

- Stress

- Dangerous

7. When people see you with a dog, they often to you.

- Listen

- Speak

- Come 
8. Dogs help people and can stay with people.

- True

- False

9. Cats are man's best friend.

- True

- False

10. A dog can always stay with you, even when your friends may forget you.

- True

- False

11. People with dogs may live a short life.

- True

- False

12. Dogs are the best cure for stress.

- True

- False

13. Friendship with dogs makes people strong.

- True

- False

14. People run away from you, when they see you with a dog.

- True

- False

\section{APPENDIX 2}

Speaking Test Task

Please describe what you see in these two pictures and the differences between the two pictures. The images are available at the following link: https://www.scribd.com/document/372380143/Flyers-Sample-Test-4. (Accessed 18 June 2021) 


\section{APPENDIX 3}

Interview Questions (research questions addressed in this article are in bold)

Demographic information:

1. How old are you?

2. What grade are you in?

3. How long have you been living in Canada?

Adaptation difficulties:

4. Did you want to leave Ukraine and move to Canada? Please explain why/why not?

5. How did you imagine the life in Canada before moving here? Were your expectations met when you arrived here?

6. Could you please tell me about the main difficulties you have experienced after arriving to Canada?

7. Did you have any difficulties with English? Please tell me more about some specific situations when you experienced difficulties with English usage.

English proficiency:

8. Have you ever attended the ESL classes? Were the ESL classes helpful? In what way were the ESL classes helpful?

9. What aspect(s) of English (reading, writing, speaking, or listening) were the most difficult for you?

10.What is the specific motivation for you to speak fluent English? Please tell me why you think so?

11. Had anything changed since you started to communicate better in English?

Current language use:

12. How many English-speaking friends do you have right now? Do you have any difficulties to communicate with them?

13. How many Ukrainian and Russian-speaking friends do you have? What language do you speak with your Ukrainian (Russian) friends?

14.What language do you speak with your parents?

15. When watching TV, do you choose Ukrainian or English channels? Please explain your choice.

16. How about now? What are you doing or did to improve your level of English proficiency? 


\section{APPENDIX 4}

Questionnaire Administered to Parents

A) Background information (please insert your answer):

1. How old is your child?

2. What is the gender of your child?

3. What grade is your child in? -------

4. How long has your child been living in Canada?

5. At what age did your child arrive in Canada?

6. What type of school does your child attend? (French immersion/Catholic, public, Ukrainian bilingual, etc.)?

7. Please explain the choice of the school for your child?

8. Has your child attended ESL classes in Canada?

9. What is your gender? -----------

10. What is your age?

B) English proficiency and adaptation (please check the box that applies in your case):

1. How important is English for your child to be accepted in Canadian society?

$\square$ Crucial $\square$ Very important $\square$ Moderately important $\square$ Slightly important $\square$ Unimportant

2. How important is English for your child's good performance at school? $\square$ Crucial $\square$ Very important $\square$ Moderately important $\square$ Slightly important $\square$ Unimportant

3. How important is English for your child to become successful in his/her future career?

$\square$ Crucial $\square$ Very important $\square$ Moderately important $\square$ Slightly important $\square$ Unimportant

4. How important is English for your child's communication with friends? $\square$ Crucial $\square$ Very important $\square$ Moderately important $\square$ Slightly important Unimportant 
5. Because of his/her level of English proficiency has your child experienced any difficulties with finding friends?

$\square$ Never $\square$ Sometimes $\square$ Often $\square$ Always

6. Because of his/her level of English proficiency has your child experienced any difficulties with understanding teachers' instructions?

$\square$ Never $\square$ Sometimes $\square$ Often $\square$ Always

7. Because of his/her level of English proficiency has your child experienced any difficulties with academic performance at school?

$\square$ Never $\square$ Sometimes $\square$ Often $\square$ Always

8. Because of his/her level of English proficiency has your child experienced any difficulties with understanding Canadian culture?

$\square$ Never $\square$ Sometimes $\square$ Often $\square$ Always

9. Because of his/her level of English proficiency has your child experienced any difficulties with attending extracurricular activities?

$\square$ Never $\square$ Sometimes $\square$ Often $\square$ Always

10. Because of his/her level of English proficiency has your child experienced any difficulties with being understood by his/her peers?

$\square$ Never $\square$ Sometimes $\square$ Often $\square$ Always 